\title{
Current understanding and applications of the cold sintering process
}

\author{
Tong Yu' ${ }^{1}$, Jiang Cheng ${ }^{2}$, Lu Li ${ }^{2}$, Benshuang $\mathrm{Sun}^{3}$, Xujin Bao ${ }^{1}$, Hongtao Zhang (凶) ${ }^{1}$ \\ 1 Department of Materials, Loughborough University, Loughborough, LE11 3TU, UK \\ 2 Research Institute for New Materials Technology, Chongqing University of Arts and Sciences, Chongqing 402160, China \\ 3 Henan Province Industrial Technology Research Institute of Resources and Materials, Zhengzhou University, Zhengzhou 450001, China
}

(C) The Author(s) 2019. This article is published with open access at link.springer.com and journal.hep.com.cn

\begin{abstract}
In traditional ceramic processing techniques, high sintering temperature is necessary to achieve fully dense microstructures. But it can cause various problems including warpage, overfiring, element evaporation, and polymorphic transformation. To overcome these drawbacks, a novel processing technique called "cold sintering process (CSP)" has been explored by Randall et al. CSP enables densification of ceramics at ultra-low temperature $\left(\leqslant 300^{\circ} \mathrm{C}\right)$ with the assistance of transient aqueous solution and applied pressure. In CSP, the processing conditions including aqueous solution, pressure, temperature, and sintering duration play critical roles in the densification and properties of ceramics, which will be reviewed. The review will also include the applications of CSP in solid-state rechargeable batteries. Finally, the perspectives about CSP is proposed.
\end{abstract}

Keywords cold sintering process, processing variables, solid-state rechargeable batteries

\section{Introduction}

Ceramics processing techniques have been developed for centuries since the Upper Paleolithic Period [1,2]. During the long development history of ceramic processing, heating is used as the dominate energy source for densification. The driving force of densification is the reduction in surface Gibbs free energy or chemical potential of the ceramics ensemble [3]. The sintering temperatures for conventional sintering techniques are typically in the range of $50 \%$ to $75 \%$ of ceramic melting points. Due to high melting points of most of ceramics, the sintering temperature is normally above $1000^{\circ} \mathrm{C}$ [2]. In

Received December 1, 2018; accepted February 21, 2019

E-mail: h.zhang3@lboro.ac.uk addition, due to the slow solid-state diffusion process, the required time for densification is usually hours or days [2]. The high temperature and long duration could cause problems accompanying with densification, including warpage, overfiring, element evaporation, and polymorphic transformation [3], which have deleterious effects on properties of ceramic products. Excessive grain growth caused by overfiring can result in decrease in mechanical strength [3] and affect the various properties for the functional ceramics [4-7]. Element evaporation is a common problem for some ceramics containing volatile elements, such as $\mathrm{Na}, \mathrm{Pb}, \mathrm{Li}, \mathrm{Bi}$, and $\mathrm{K}$ [3]. In addition, long duration sintering is time- and energy-consuming [3]. Some new sintering techniques have been developed in order to reduce sintering temperatures and duration. One common way to reduce sintering temperatures is to increase the driving force of densification through applying pressure simultaneously with temperature, such as overpressure sintering [8], hot pressing $[9,10]$, and hot isostatic pressing $[11,12]$. Another approach is through utilizing electrical field to enhance diffusion processes, such as flash sintering $[13,14]$, spark plasma sintering $[15,16]$, and microwave sintering $[17,18]$. Even though the sintering temperature has been reduced to some extent, it is still quite high [19-24]. Therefore, new processing method that can densify a wide range of materials at ultra-low temperature, or even at room temperature with short duration is in demand.

Recently, Randall et al. have developed a novel ceramic processing technique called "cold sintering process" (CSP) [1]. The CSP is described as a low temperature sintering technique with assistance of transient aqueous solution and pressure. Ceramic materials with very high density can be produced at $\leqslant 300^{\circ} \mathrm{C}$ within short duration $(\sim 1 \mathrm{~h})$ [2]. The mechanism of CSP is proposed as "dissolution-precipitation" process. Aqueous solution, temperature, pressure, and duration are the four key processing variables of CSP to govern the densification process of materials. In this 
paper, mechanisms of CSP and the effects of processing conditions on densification behaviors will be reviewed. The application of CSP on solid-state rechargeable battery materials will also be discussed.

\section{Mechanisms and advantages of CSP}

\subsection{Mechanisms of CSP}

CSP of ceramics was firstly reported by Randall et al. at 2016. They proposed "dissolution-precipitation" mechanisms to describe densification of ceramics [1]. Figure 1 schematically shows the different stages involved in CSP [2]. In the first stage - particle compaction, an appropriate amount of aqueous solution is introduced to wet the surface of ceramic particles homogenously and forms a liquid film around the particles [25]. Aqueous solution enables local dissolution of the sharp surface of the particles and acts as lubricant to promote particles rearrangement and sliding [26]. With the compaction of particles by applied external pressure, the redistribution of the aqueous solution will proceed readily, and the liquid phase will fill in the particle-particle interspaces [27]. In second and third stages, dissolution-precipitation and crystal growth occur, including removing liquid phase in particle interspaces via evaporation at a temperature right above the boiling temperature of the aqueous solution [28]. The evaporation of liquid phase enables a supersaturated state at particle interspaces, and the chemical potential at contact area is higher than that at crystal sites [1]. Therefore, the dissolved atomic clusters and/or ionic species will precipitate on crystal sites and contribute to densification of ceramics [25]. In addition to the formation of well-crystallised structure at crystal sites, non-equili- brium phases are probably formed, such as metastable compound or glass phase [29]. The reason is that the nucleation rate in metastable phase is higher than that in stable phases [2]. In this case, the supersaturated solution will nucleate a less stable amorphous phase and further suppress the crystallisation [25]. From energy demand point of view, the liquid phase mass transport minimizes the demand for Gibbs free energy change for sintering [2]. A Gibbs free energy diagram in a single component system is shown in Fig. 2. Compared to conventional sintering, the Gibbs free energy change for crystallisation from an aqueous solution to form a solid is significantly lower.

\subsection{Advantages of CSP}

The advantages of CSP over other sintering processes can be summarized [25-29]: (i) Ultra-low sintering temperature $\left(\leqslant 300^{\circ} \mathrm{C}\right)$ due to facilitated mass transport kinetics by mechanical-chemical couplings. (ii) Capability to fabricate nanostructured ceramics due to ultra-low sintering temperature and short duration. (iii) Great potential on cosintering of dissimilar materials with large difference in processing temperature window. For example, ceramic/ polymer composites can be easily produced by CSP. (iv) Low energy consumption and simple experimental setup.

\section{Effects of processing variables}

In CSP, densification of materials is affected by several chemical and physical factors, including aqueous solution, applied pressure, temperature, and duration. Each factor plays individual role in different stages of CSP and facilitates densification with different mechanisms. Understanding of the effect of each processing variables on
Stage 1

Particle compaction

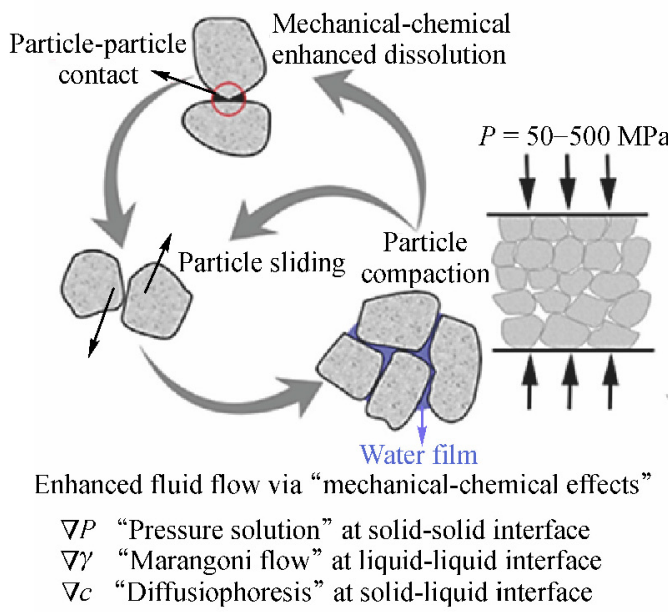

Stage II \& III

dissolution-precipitation \& crystal growth

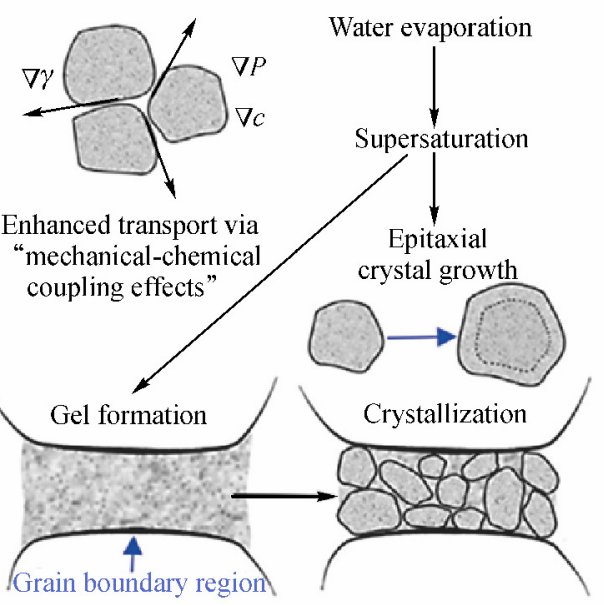

Fig. 1 Schematics of CSP mechanism at various stages. Reproduced from ref. [2] with permission, copyright 2016 John Wiley and Sons. 


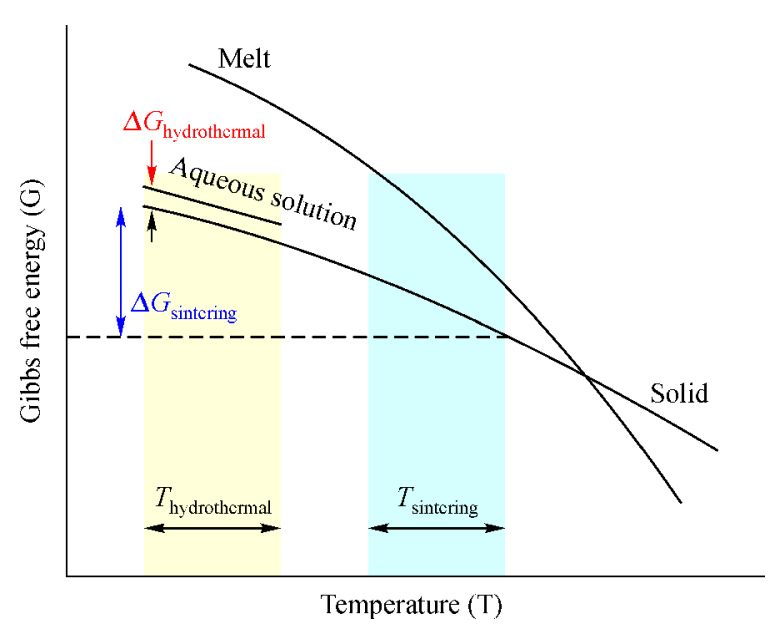

Fig. 2 Diagram of Gibbs free energy in a single component system. Reproduced from ref. [30] with permission, copyright 2001 Elsevier.

densification and properties of materials are important for the further development of CSP.

\subsection{Effect of aqueous solution}

Establishing a proper aqueous solution, including nature of the solute, $\mathrm{pH}$ value, and solute concentration, enables a favorable environment for chemical reaction, induce grain boundary defects, and reduce activation energy for mass transport in the initial stages of CSP. Comparing with solid-state sintering, in which mass transport is facilitated mainly by high temperature [3], aqueous solution in CSP enables ions/atom mass transport in liquid phase, which is a more efficient way than solid-state transport. The mass transport in solid and liquid phase can be further explained by diffusivity, which is represented as $D_{\mathrm{gb}} \delta_{\mathrm{gb}}$ for grain boundary diffusion in solid state sintering and $D_{\mathrm{L}} \delta_{\mathrm{L}}$ in liquid phase sintering, where $D_{\mathrm{gb}}$ and $D_{\mathrm{L}}$ are diffusion coefficients of atoms at grain boundary and liquid, respectively. $\delta_{\mathrm{gb}}$ is the thickness of surface diffusion, and $\delta_{\mathrm{L}}$ is the width of the liquid bridge [31]. As the $\delta_{\mathrm{L}} \gg \delta_{\mathrm{gb}}$ and $D_{\mathrm{L}} \gg D_{\mathrm{gb}}$, the mass transport in liquid phase is significantly enhanced comparing with solid-state sintering. The pre-condition for ions/atoms mass transport in CSP is dissolution of particle surfaces in an aqueous solution.

Hygroscopic substances, including $\mathrm{KH}_{2} \mathrm{PO}_{4}$ [2], $\mathrm{NaNO}_{2}$ [2], $\mathrm{NaCl}$ [32], carbonate materials [33], and alkali molybdates [1] $\left(\mathrm{Li}_{2} \mathrm{MoO}_{4}, \mathrm{Na}_{2} \mathrm{Mo}_{2} \mathrm{O}_{7}, \mathrm{~K}_{2} \mathrm{Mo}_{2} \mathrm{O}_{7}\right)$ can easily dissolve in water [2]. Thus, they can be easily densified to achieve high density ( $>90 \%$ ) by CSP from a temperature as low as room temperature to $120^{\circ} \mathrm{C}$. The solubility of a material in water can be evaluated by solubility product constant $\left(K_{\mathrm{sp}}\right)$ [34]. For example, for an $A_{a} B_{b}$ insoluble electrolyte in water, the equilibrium condition and the $K_{\mathrm{sp}}$ can be represented as:

$$
\begin{gathered}
A_{a} B_{b} \rightleftharpoons a A^{n+}+b B^{m-}, \\
K_{\mathrm{sp}}=\left[A^{n+}\right]^{a}\left[B^{m-}\right]^{b},
\end{gathered}
$$

where, $\left[A^{n+}\right]$ and $\left[B^{m-}\right]$ are the concentrations of respective ions dissociated in water. Generally, the larger solubility of a material in water, the higher concentration of dissociated ions, hence the higher $K_{\mathrm{sp}}$ value. In other words, a material with lower $K_{\mathrm{sp}}$ is more difficult to dissolve in water [34]. To dissolve the insoluble solid, the ion product in water has to be smaller than $K_{\mathrm{sp}}$ to deviate the equilibrium condition [34]. This can be achieved by reducing one of the ionic concentrations $\left(\left[A^{n+}\right]\right.$ or $\left.\left[B^{m-}\right]\right)$ to push the reaction to shift from left to right (solid to ions) in Eq. (1). One way to reduce the ionic concentration is to introduce other materials that can react with one of the ions to form a weak electrolyte with low degree of dissociation [34], for example, acid. Taking $\mathrm{Mg}(\mathrm{OH})_{2}$ as an example, $\mathrm{Mg}(\mathrm{OH})_{2}$ is a kind of insoluble electrolyte and will slightly dissociate forming $\mathrm{Mg}^{2+}$ and $\mathrm{OH}^{-}$in water. With addition of $\mathrm{HCl}$, the $\mathrm{OH}^{-}$will react with $\mathrm{H}^{+}$provided by dissociation of $\mathrm{HCl}$ to form $\mathrm{H}_{2} \mathrm{O}$. This reaction will force $\mathrm{Mg}(\mathrm{OH})_{2}$ to continually dissociate to provide $\mathrm{OH}^{-}$. This mechanism explains the dissolution of insoluble materials in acid/alkali solutions. Based on this mechanism, acid and alkali solution can be applied in CPS to increase solubility of the insoluble materials. For example, $2 \mathrm{~mol} \cdot \mathrm{L}^{-1} \mathrm{LiOH}$ and ammonia solution with $\mathrm{pH}$ value of 10.5 were used for densification of $\mathrm{LiFePO}_{4}$ [35] and $\mathrm{InGaZnO}_{4}$ target [29] by CSP, respectively. Whereas, acetic acid was chosen for densification of $\mathrm{ZnO}$ [36]. The determination of $\mathrm{pH}$ value or concentration of acid/alkali solutions depends on the solubility of a material at different $\mathrm{pH}$ values. Most of materials show different chemical species in solutions as a function of $\mathrm{pH}$ values. For example, according to the phase stability diagram for $\mathrm{BaTiO}_{3}-\mathrm{H}_{2} \mathrm{O}-\mathrm{CO}_{2}$ system (Fig. 3) [37], $\mathrm{BaTiO}_{3}$ is stable phase above about $\mathrm{pH} 12$ if the $\mathrm{pCO}_{2}$ is less than 4.5. But it is easy to be dissolved as cations at $\mathrm{pH}<12$ and its solubility increases with decreasing of $\mathrm{pH}$ value [37]. Generally, the dissolution of materials increases with increasing acid/alkali concentration. Therefore, concentration of acid/alkali solution is critical for the densification during CSP. A much higher density ( $>90 \%$ ) of $\mathrm{ZnO}$ was observed when $1 \mathrm{~mol} \cdot \mathrm{L}^{-1}$ acetic acid solution was used, compared to that $(65 \%)$ when water or $0.1 \mathrm{~mol} \cdot \mathrm{L}^{-1}$ acetic acid was used [38]. Gonzalez-Julian et al. [36] also reported that an acid solution with high concentration is beneficial to fast sintering rate as well as reduction in onset temperature of densification. This is attributed to the formation of grain boundary defect due to diffusion of $\mathrm{H}^{+}$and $\mathrm{OH}^{-}$ions from dissociation of water into crystals [36]. In addition to proper selection of acid/alkali solutions, there are still other ways to increase solubility of ceramic powders in aqueous 


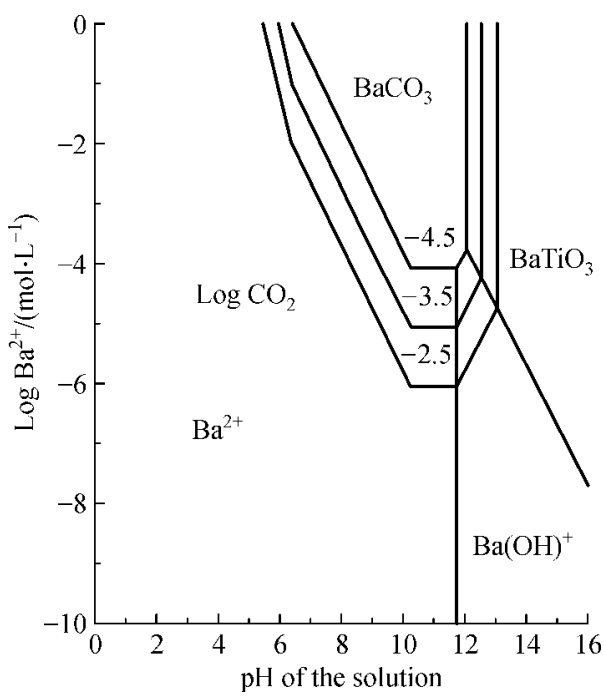

Fig. 3 Theoretical predominance diagram for $\mathrm{BaTiO}_{3}-\mathrm{H}_{2} \mathrm{O}$ $\mathrm{CO}_{2}$ system. Reproduced from ref. [37] with permission, copyright 2005 John Wiley and Sons.

solution, such as increasing temperature and reducing particle size. Since the $K_{\mathrm{sp}}$ increases with increasing temperature [34], high temperature can enhance the dissolution to some extent. The dependence of solubility of the solid phase in the liquid on its particle size follows Ostwald-Freundlich equation [31]:

$$
\ln \frac{S_{r}}{S_{\infty}}=\frac{2 \Omega \gamma_{\mathrm{s} 1}}{k T r}
$$

where, $S_{r}$ is the solubility of particle with radius $r, S_{\infty}$ is the solubility of particle with infinite radius, $\gamma_{\mathrm{s} 1}$ is the interfacial tension, $\Omega$ is the atomic volume, $k$ is the Boltzmann constant, and $T$ is absolute temperature. Above equation indicates that the solubility $\left(S_{r}\right)$ of nanoparticles can substantially increase due to the Gibbs-Thomson effect. In addition, nanoparticles provide more lattice sites for dissolution process and nucleation during precipitation due to the high surface-to-volume ratio [2]. As a result, nanoparticles are beneficial to enhanced dissolution and densification during CSP [39].

For some ultra-stable compounds with very low solubility product constants $\left(K_{\mathrm{sp}}\right)$, such as $\mathrm{Pb}(\mathrm{Zr}, \mathrm{Ti}) \mathrm{O}_{3}$, a transient solution containing corresponding cations can be used as an alternative to water or acid/alkali solutions in order to generate a saturated solution environment and form the same composites as final products. For example, Wang et al. [40] used $\mathrm{Pb}\left(\mathrm{NO}_{3}\right)_{2}$ solution for densification of $\mathrm{Pb}(\mathrm{Zr}, \mathrm{Ti}) \mathrm{O}_{3}$ by $\mathrm{CSP}$ under $500 \mathrm{MPa}$ at $300^{\circ} \mathrm{C}$, and $89 \%$ of theoretical density was achieved. Moreover, to densify some ternary compounds with the cations having extremely large different dissolution properties, a suspension containing the cations and precursor oxide nanoparticles can be employed. For example, to densify $\mathrm{BaTiO}_{3}$ $[2,25,41]$, "hydrothermal precursor solution" [42] - Ba
$(\mathrm{OH})_{2} / \mathrm{TiO}_{2}$ suspension was used to provide a $\mathrm{Ba}^{2+}$ rich environment in order to impede both the leaching of $\mathrm{Ba}^{2+}$ and the formation of $\mathrm{TiO}_{2}$ passive layer, which hinder the mass diffusion and densification [43]. Meanwhile, the adding of $\mathrm{TiO}_{2}$ in solution guarantees the formation of $\mathrm{BaTiO}_{3}$. After CSP, $90 \%$ of theoretical density was achieved. Similar suspension of $\mathrm{SrCl}_{2} / \mathrm{TiO}_{2}$ nanoparticles was used in densification of $\mathrm{SrTiO}_{3}$ by CSP [44]. The infilling micro-reactions between $\mathrm{TiO}_{2}$ and $\mathrm{SrCl}_{2}$ occurred around grains and high density $(\sim 97 \%)$ was achieved after CSP and post-annealing [44].

Nonaqueous solvents, such as organic solvents with low boiling temperature $\left(<200^{\circ} \mathrm{C}\right)$, have also been employed in CSP. The low boiling temperature guarantees the low processing temperature of CSP. For example, Berbano et al. [45] used ethanol as a substitute for water in CSP of $\mathrm{Li}_{1.5} \mathrm{Al}_{0.5} \mathrm{Ge}_{1.5}\left(\mathrm{PO}_{4}\right)_{3}$ solid electrolyte. The density $(\sim 75 \%)$ and ionic conductivity $\left(6.5 \times 10^{-6} \mathrm{~S} \cdot \mathrm{cm}^{-1}\right)$ of $\mathrm{Li}_{1.5} \mathrm{Al}_{0.5} \mathrm{Ge}_{1.5}\left(\mathrm{PO}_{4}\right)_{3}$ produced by using ethanol were comparable to those produced by using water. Sato et al. [46] has proposed an organic solvent family with long-pair electron orbital and an opposite proton donor site as solvents for CSP of Zr-based ceramics. Such organic solvents include formamide, propylamine, ethanolamine, ethanol, and glycerol, etc. [47].

\subsection{Effect of pressure, temperature, and duration}

The processing parameters, such as applied pressure, temperature, ramp rate, and sintering duration, play roles in providing an effective driving force for mass transport and controlling grain growth.

Pressure is a crucial parameter in CSP since it contributes to distribution of liquid phase, the reorientation, sliding, and compaction of particles, which lead to higher densification rates and controlled grain sizes. The effect of pressure on density of $\mathrm{NaCl}$ [32] and $\mathrm{Na}_{3.256} \mathrm{Mg}_{0.128} \mathrm{Zr}_{1.872} \mathrm{Si}_{2} \mathrm{PO}_{12}$ (Mg-doped NASICON) [48] produced by CSP was studied. It was found that the densities increased with applied pressure (Fig. 4). Gonzalez-Julian et al. [36] reported that the increasing applied pressures can reduce the onset temperature of densification, and thus restrain the grain growth during densification. This has been confirmed in the studies of $\mathrm{NaCl}$ [32] and $\mathrm{ZnO}$ [38] produced by CSP. Fully dense ceramics with controlled grain size are always desirable for the performance of ceramics [49-51].

High temperature in CSP provides energy for mass transport, liquid phase evaporation, and grain growth. Densification rate of cold-sintered materials varies with different temperature range. The densification rate initially increases quite fast with increasing sintering temperature, then is gradually stagnant with further increasing temperature (Fig. 5) [45]. The variation of densification rate with temperature is associated with the evaporation rate of liquid phase at different temperatures. The densification 


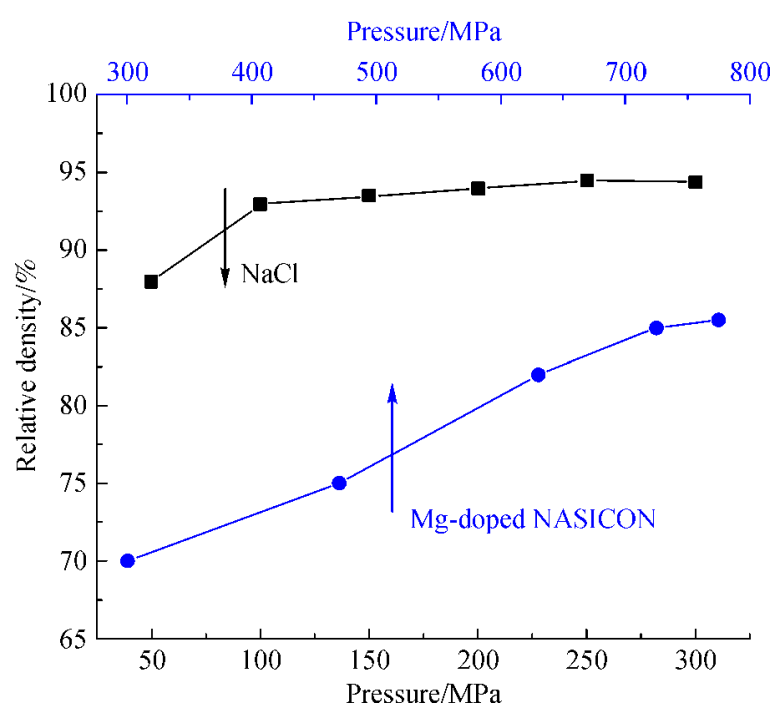

Fig. 4 Plots of relative density vs. pressure of $\mathrm{CSP}$ of $\mathrm{NaCl}$ and Mg-doped NASICON. Reproduced from ref. [32] and ref. [48] with permissions, copyright 2005 John Wiley and Sons, and 2018 Elsevier.

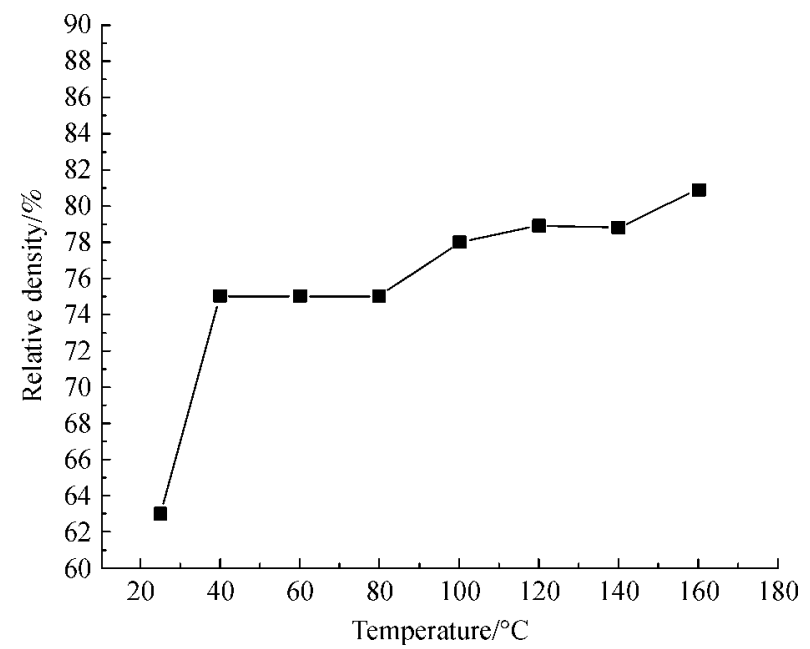

Fig. 5 Plots of relative density vs. temperature of $\mathrm{Li}_{1.5} \mathrm{Al}_{0.5} \mathrm{Ge}_{1.5}\left(\mathrm{PO}_{4}\right)_{3}$. Reproduced from ref. [45] with permission, copyright 2017 John Wiley and Sons.

process may slow down at high temperature since the amount of water/solution decreases by evaporation [48]. Gonzalez-Julian [36] studied the effect of the rate of heating ramp on densification in CSP and found that more water can be retained under fast heating rate at high temperature, hence promoted densification (Table 1) [36]. To prove this, further experimental works was conducted. The density was not increased by simply increasing the pressure (from 150 to $300 \mathrm{MPa}$ ). By adding doubled amount of water in the system to compensate the early loss of the water due to evaporation under slow heating rate, $\mathrm{ZnO}$ with high density of $93.4 \%$ was successfully produced [36]. The water loss during CSP also results in the similar change in density vs sintering duration. The density of most ceramics usually increases within the first one hour and levels off after that period [38].

\subsection{Effect of post-annealing}

Fully densified structures may not be achieved for some ceramic materials by just one-step CSP due to the limited dissolution and formation of amorphous or second phase in the grain boundaries. In this case, a post-annealing process is necessary to increase the crystallinity, eliminate the amorphous/second phase, and finally increase the density. Post-annealing temperature and time depend on the crystallisation temperatures of glass. When $\mathrm{BaTiO}_{3}$ was produced by CSP [25], a second phase, $\mathrm{BaCO}_{3}$, was formed along grain boundaries between crystalline $\mathrm{BaTiO}_{3}$ grains in as-CSPed sample due to the reaction between $\mathrm{Ba}^{2+}$ and $\mathrm{CO}_{2}$ in atmosphere (Fig. 6(a)) [25]. To eliminate second phase and glass phase, the samples were annealed at $700^{\circ} \mathrm{C}-900^{\circ} \mathrm{C}$ [26]. The glass phase is significantly reduced in content after annealing at $700^{\circ} \mathrm{C}$ (Fig. 6(b)) and almost completely removed after annealing at $900^{\circ} \mathrm{C}$ (Fig. 6(c)). Similar phenomenon was also observed in CSP of $\mathrm{Pb}(\mathrm{Zr}, \mathrm{Ti}) \mathrm{O}_{3}$ [40]. A second phase, $\mathrm{PbO}$, was found in as-CSPed sample, and the relative density was $89 \%$. After annealed at $900^{\circ} \mathrm{C}$, the second phase was eliminated, and the density increased up to $99 \%$. Leng et al. [48] compared the effect of post-annealing after CSP and conventional sintering (dry press) on the density of Mg-doped NASICON. At the same annealing (sintering) temperature $\left(<1200^{\circ} \mathrm{C}\right)$, the samples produced by post-annealing after CSP exhibit higher density than those produced by conventional sintering, which demonstrates the important role of initial CSP step on final density (Fig. 7(a)). Even though the post-annealing temperature is much higher than cold sintering temperature, it is still lower than conventional sintering temperature.

Table 1 Summary of CSP conditions and relative densities of ZnO samples by field assisted sintering technique (FAST)/spark plasma sintering (SPS) and hand pressing techniques. Reproduced from ref. [36] with permission, copyright 2018 Elsevier.

\begin{tabular}{|c|c|c|c|c|c|c|}
\hline Techniques & Composition & $\begin{array}{l}\text { Water content } \\
/ \text { wt- } \%\end{array}$ & $\begin{array}{l}\text { Heating rate } \\
/\left({ }^{\circ} \mathrm{C} \cdot \min ^{-1}\right)\end{array}$ & $\begin{array}{l}\text { Pressure } \\
/ \mathrm{MPa}\end{array}$ & $\begin{array}{l}\text { Holding time } \\
/ \mathrm{min}\end{array}$ & $\begin{array}{l}\text { Relative density } \\
1 \%\end{array}$ \\
\hline \multirow[t]{2}{*}{ FAST/SPS } & $\mathrm{ZnO} / \mathrm{H}_{2} \mathrm{O}$ & 1.6 & 100 & 150 & 5 & 91.8 \\
\hline & & 1.6 & 20 & 150 & 5 & 87.9 \\
\hline \multirow[t]{2}{*}{ CSP } & & 1.6 & 20 & 300 & 5 & 88.0 \\
\hline & & 3.2 & 20 & 300 & 5 & 93.4 \\
\hline
\end{tabular}


Cold sintered at $180^{\circ} \mathrm{C}$

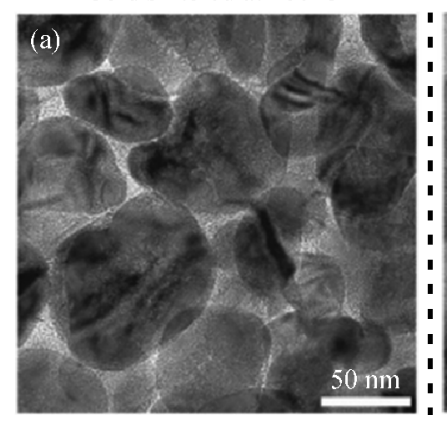

Annealed at $700^{\circ} \mathrm{C}$

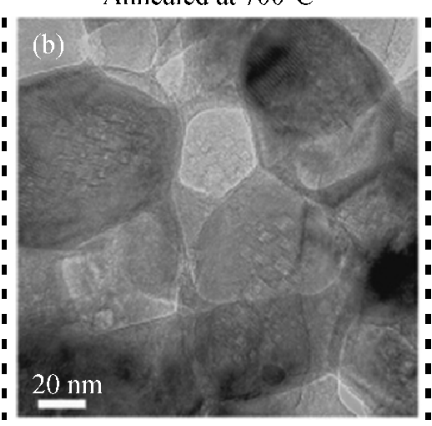

Annealed at $900^{\circ} \mathrm{C}$

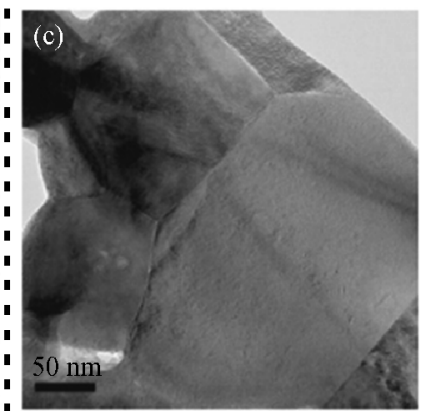

Fig. 6 TEM images of microstructure evolution of $\mathrm{BaTiO}_{3}$ cold-sintered at $180^{\circ} \mathrm{C}$ and annealed at $700^{\circ} \mathrm{C}$ and $900^{\circ} \mathrm{C}$. Reproduced from ref. [25] with permission, copyright 2016 American Chemical Society.
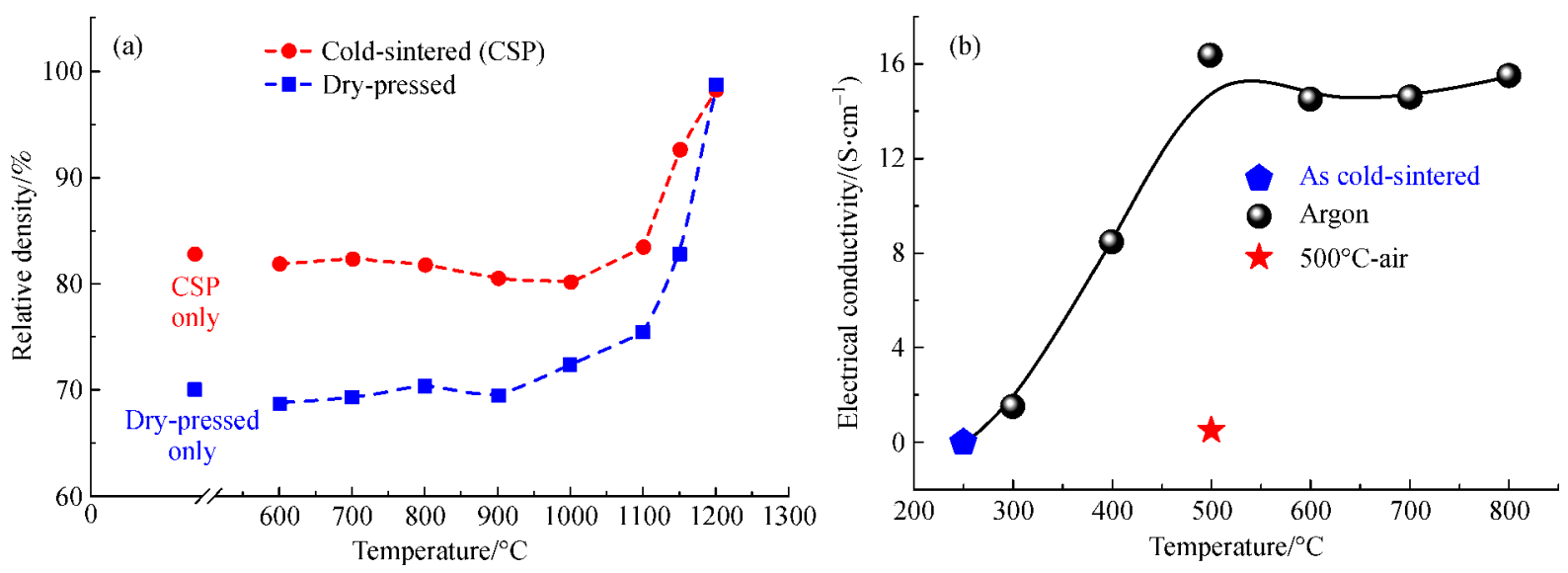

Fig. 7 (a) Plot of relative density vs. temperature of cold-sintered and dry-pressed Mg-doped NASICON specimens. Reproduced from ref. [48] with permission, copyright 2018 Elsevier; (b) Electrical conductivity of ZnO sample after cold sintered and post-annealed at different temperatures in argon and air. Reproduced from ref. [52] with permission, copyright 2018 Elsevier.

The post-annealing process is expected to improve performance of CSPed ceramics due to enhanced density and crystallinity. Jing et al. [52] reported the improved electrical conductivity of CSPed $\mathrm{ZnO}$ ceramics by postannealing in controlled atmosphere. After cold sintered at $250^{\circ} \mathrm{C}$ under $350 \mathrm{MPa}$ for $1 \mathrm{~h}, \mathrm{ZnO}$ ceramics showed high density $(97.5 \%)$, but very low electrical conductivity of $0.0005 \mathrm{~S} \cdot \mathrm{cm}^{-1}$. After annealed at $500^{\circ} \mathrm{C}$ in argon atmosphere, the conductivity increased up to $16.4 \mathrm{~S} \cdot \mathrm{cm}^{-1}$ (Fig. 7(b)) [52]. The improvement in electrical conductivity is mainly attributed to the increase in the crystallinity of $\mathrm{ZnO}$, the concentration of oxygen vacancies and interstitial zinc atoms due to desorption of oxygen on grain boundaries by annealing in argon atmosphere.

\subsection{Effect of CSP variables on composite materials}

Dense ceramic/ceramic or ceramic/polymer composites with uniform microstructure are usually difficult to be produced by conventional co-sintering due to significant mismatch in constitutes' properties, such as melting temperature, thermal expansion coefficient, etc. As the processing temperature can be controlled under $300^{\circ} \mathrm{C}$ in
CSP, it makes the one-step co-sintering of dissimilar materials possible. At present, several ceramic/ceramic composites [53-55] and ceramic/polymer composites $[27,56,57]$ have been fabricated by CSP in order to improve density and electrical properties, such as relative dielectric permittivity [54], microwave quality factor (Qf) [53], breakdown strength [57], and electrical conductivity [58].

The pre-condition for densification of composite materials by CSP is still dissolution, which is the same for monolithic ceramic. However, as two or more constitutes with different solubility are involved in composites, it is difficult to achieve simultaneous dissolution of all constitutes. Thus, as long as one of the constitutes is soluble, it is possible to achieve densification of composites by CSP. For example, $\mathrm{NaCl}$ and $\mathrm{Li}_{2} \mathrm{MoO}_{4}$ (LMO) were chosen as soluble additives to produce $\mathrm{Al}_{2} \mathrm{O}_{3} / \mathrm{NaCl}$ [55], $\mathrm{Al}_{2} \mathrm{SiO}_{5} / \mathrm{NaCl}$ [54], and $\mathrm{Na}_{0.5} \mathrm{Bi}_{0.5} \mathrm{MoO}_{4} / \mathrm{Li}_{2} \mathrm{MoO}_{4}(\mathrm{NBMO} / x \mathrm{LMO})$ [53] composites by CSP. In Induja's work [54], the density of $\mathrm{Al}_{2} \mathrm{SiO}_{5} / \mathrm{NaCl}(1: 1$ vol-\%) composites was reported to be $91.2 \%$ after $\mathrm{CSP}$ at $120^{\circ} \mathrm{C}$. In comparison, the density of monolithic $\mathrm{Al}_{2} \mathrm{SiO}_{5}$ ceramic produce by conventional 
sintering at $1525^{\circ} \mathrm{C}$ was only $64.5 \%$. The density of coldsintered $\mathrm{NBMO} / x \mathrm{LMO}$ composites $(x=0-100 \mathrm{wt}-\%)$ as a function of the content $x$ of soluble LMO was studied [53]. The relative density increased from $84.9 \%$ to $96.4 \%$ with increasing content of LMO from $0-100 \mathrm{wt}-\%$ at the same processing conditions. The addition of LMO in composites not only increases their density, but also improve the microwave properties of $\mathrm{NBMO} / x \mathrm{LMO}$ composites. The relative dielectric permittivity of $\mathrm{NBMO} / x \mathrm{LMO}$ composites decreased from 24.1 to 5.3 and Qf increased from 2236 to $24319 \mathrm{GHz}$ with increasing amount of LMO from 10 to $100 \mathrm{wt}-\%$ [53].

For ceramic/polymer composites, the dissolution process is mainly determined by ceramic matrix in CSP, due to the insolubility of most of polymers in aqueous solutions. Therefore, the effect of aqueous solution on densification behaviors of ceramic/polymer composites is similar to that of monolithic ceramic materials. For example, because acetic acid was used for densification of monolithic $\mathrm{ZnO}$ by CSP [52], $\mathrm{ZnO}$ /polytetrafluoroethylene (PTFE) was cold-sintered with $2 \mathrm{~mol} / \mathrm{L}$ of acetic acid to achieve high density of $92 \%-97 \%$ [27]. PTFE is an insulating phase segregating in intergranular regions to limit the conduction across grain boundary and achieve varistor behaviors. The grain boundary resistivity increased up to $1.5 \times 10^{6} \Omega$ when 10 vol-\% of PTFE was added [27]. $\mathrm{Na}_{2} \mathrm{Mo}_{2} \mathrm{O}_{7} /$ poly(ether imide) (PEI) [57] composite with high density of $>90 \%$ was produced by CSP using water as transient solvent. The dielectric breakdown strength of $\mathrm{Na}_{2} \mathrm{Mo}_{2} \mathrm{O}_{7} /$ PEI composite increased from 55.1 to $120 \mathrm{MV} \cdot \mathrm{m}^{-1}$ when the content of PEI increased from 0-40 vol-\% [57]. Although the addition of polymer with appropriate amount can improve the electrical properties of ceramic/polymer composites, excess amount of polymer will result in agglomeration of polymers and heterogeneous separation of ceramics and polymers [57].

\section{Applications of CSP on solid-state rechargeable batteries}

CSP has been applied to sinter a wide range of materials including ferroelectric materials, piezoelectric materials, semi-conductive materials, and energy storage materials, etc. $[25-29,33,34,36,37,39-42,45,46,48,52-62]$. The applications of above materials are extremely broad, such as capacitors, actuators, oxygen sensor [26], protect sensitive electronic devices [38], touch panels [63], solar cells [64], thermoelectric devices [65], and solid-state rechargeable batteries [48], etc. Considering that solidstate rechargeable batteries have received intensive attentions due to their high energy density and excellent safety over liquid counterparts for electric vehicle applications [66-68], we mainly focus on the recent works on electrodes and electrolytes for solid-state rechargeable batteries produced by CSP.
Two cathode materials, $\mathrm{LiFePO}_{4}$ (LFP) $[35,60]$ and $\mathrm{V}_{2} \mathrm{O}_{5}[56,58]$, have been fabricated by CSP in order to increase density and electrical properties. A traditional processing technique to fabricate cathode coating with 20 $40 \mathrm{wt}-\%$ of conductive carbon black and polymer binders is tape-casting [60], which results in the low volumetric capacity density. Seo et al. [60] used CSP to fabricate both monolithic LFP and LFP cathode composites pellets. The theoretical density of monolithic LFP pellets produced by CSP was $85 \%$, which was much higher than that $(\sim 64 \%)$ of pellets produced by dry-press under the same pressure and temperature [35]. Similarly, LFP cathode composite pellets with 10 wt- $\%$ of conductive carbon and 10 wt- $\%$ of PVDF produced by CSP exhibited higher density $(\sim 89 \%)$ than that $(\sim 62 \%)$ of composite pellets with same formulation produced by tape-casting [35]. The enhanced density of LFP cathode composite pellets led to the significant improvement in volumetric capacity $\left(\sim 340 \mathrm{mAh} \cdot \mathrm{cm}^{-3}\right.$ for CSP vs. $\sim 159-227 \mathrm{mAh} \cdot \mathrm{cm}^{-3}$ for tape-casting) at the same discharge rate $(0.1 \mathrm{C})$. In addition, the cold sintered cathode composites also show good cycling performance. $87 \%$ of initial capacities were preserved after 40 cycles [60]. To fabricate thin film LFP cathode composites with high density of $70 \%$, Seo combined tape-casting with CSP. High volumetric capacities, 373 and $247 \mathrm{mAh} \cdot \mathrm{cm}^{-3}$, were achieved at low $(0.1 \mathrm{C})$ and high $(10 \mathrm{C})$ charge/discharge rates, respectively [60]. Moreover, the cycling performance of the thin film cathode was also very good due to the high density and structural stability. Over $90 \%$ of initial capacity was retained after 100 cycles even at high current rate of $10 \mathrm{C}$ [60]. $\mathrm{V}_{2} \mathrm{O}_{5}$ is a semiconductor with layered crystal structure, which allows the intercalation of $\mathrm{Li}^{+}$, and thus can be used as cathode for lithium ion battery [69]. Conductive polymer, such as polyaniline, is commonly added to increase the electrical conductivity and stability of $\mathrm{V}_{2} \mathrm{O}_{5}$ [70]. Due to the large difference in process temperature window between $\mathrm{V}_{2} \mathrm{O}_{5}$ and polymer, the fabrication of above composites is challenging. CSP was applied to produce $\mathrm{V}_{2} \mathrm{O}_{5}$ /poly(3,4-ethylenediox-ythiophene) polystyrene sulfonate (PEDOT : PSS) composites with a high density of $90.2 \%$. The electrical conductivity of monolithic $\mathrm{V}_{2} \mathrm{O}_{5}$ was $4.8 \times 10^{-4} \mathrm{~S} \cdot \mathrm{cm}^{-1}$ [58]. However, the electrical conductivity of the composites with 1-2 vol-\% of PEDOT:PSS increased up to $10^{-2} \mathrm{~S} \cdot \mathrm{cm}^{-1}$ [56].

When ceramic electrolytes are produced by the traditional sintering technique, high temperature is necessary to increase the density and ionic conductivity through minimizing grain boundary area and further reduce grain boundary resistivity [45]. However, high temperature process may cause volatile element (e.g., Li) evaporation and formation of second phase. On the contrast, CSP enables to densify electrolytes with pure phase and high ionic conductivity at much lower temperature. A proton electrolyte $\mathrm{CsH}_{2} \mathrm{PO}_{4}$ with $98 \%$ of theoretical density and high proton conductivity $\left(2.3 \times 10^{-4} \mathrm{~S} \cdot \mathrm{cm}^{-1}\right)$ was produced by CSP at $200^{\circ} \mathrm{C}$, which was lower than the 
dehydration temperature $\left(230^{\circ} \mathrm{C}\right)$ of $\mathrm{CsH}_{2} \mathrm{PO}_{4}$ [61]. Postannealing is often used after CSP to eliminate insulating amorphous phase at grain boundaries in order to enhance ionic conductivity. $\mathrm{Mg}$-doped NASICON solid-state electrolyte with composition of $\mathrm{Na}_{3.256} \mathrm{Mg}_{0.128} \mathrm{Zr}_{1.872} \mathrm{Si}_{2} \mathrm{PO}_{12}$ for Na-ion battery was produced by CSP in Leng's work [48]. As-CSPed sample exhibited low conductivity $\left(0.041 \mathrm{mS} \cdot \mathrm{cm}^{-1}\right)$ due to low density $(\sim 83 \%)$ and the formation of second phase along grain boundaries [48]. After post-annealed at $1200^{\circ} \mathrm{C}$, the sample showed pure phase with the increased density ( $98 \%)$ and ionic conductivity $\left(1.406 \mathrm{mS} \cdot \mathrm{cm}^{-1}\right)$ [48]. Berbano et al. [45] used CSP to produce $\mathrm{Li}_{1.5} \mathrm{Al}_{0.5} \mathrm{Ge}_{1.5}\left(\mathrm{PO}_{4}\right)_{3}$ electrolyte with density of $79 \%$ and ionic conductivity of $7.9 \times 10^{-6}$ $\mathrm{S} \cdot \mathrm{cm}^{-1}$. The impedance spectrum was dominated by grain boundary resistance. In comparison, post-annealing at $650^{\circ} \mathrm{C}$ slightly reduced the density $(75 \%)$, but greatly increased the ionic conductivity up to $5.4 \times 10^{-5} \mathrm{~S} \cdot \mathrm{cm}^{-1}$ [45]. Finally, the CSP has high potential to fabricate ceramic/polymer composites electrolytes to increase the interface stability between electrolytes and Li metal anode [71] and develop fully integrated solid-state batteries [60]. Berbano used CSP to produce composite electrolyte consisting of $\mathrm{Li}_{1.5} \mathrm{Al}_{0.5} \mathrm{Ge}_{1.5}\left(\mathrm{PO}_{4}\right)_{3}$ and $\left(-\mathrm{CH}_{2} \mathrm{CF}_{2}-\right)_{x}$ $\left[-\mathrm{CF}_{2} \mathrm{CF}\left(\mathrm{CF}_{3}\right)-\right]_{y}$ (PVDF-HFP) [45]. Subsequently, asCSPed composites electrolytes were soaked in liquid electrolyte. As a result, the ionic conductivity of the composites reached $\sim 10^{-4} \mathrm{~S} \cdot \mathrm{cm}^{-1}$ [45]. Soaking in liquid electrolyte is crucial to increase conductivity since the polymer phase is swelled during soaking, and thus leads to increase in grain boundary contact area and provide ionic bridge for conducting of ions [45].

\section{Summary and perspectives}

In this paper, CSP mechanism, the effect of processing variables on densification behavior and properties, and the applications of CSP on solid-state rechargeable batteries are reviewed. The mechanism of the CSP is proposed to be the "dissolution-precipitation" process. Dissolution is crucial for densification during CSP since it is the precondition of mass transport within liquid phase. As the solubility of most ceramic materials is poor, several ways have been proposed for cold sintering of the insoluble ceramics, including employing acid/alkali aqueous solution or nonaqueous solvents, using nanoparticles as starting materials, introducing hydrothermal precursor solutions/suspensions. The other key processing variables include pressure, temperature, heating rate, and duration, etc. The density of ceramics usually shows positive correlation with these variables. Increasing applied pressure lead to reduction in the onset temperature of densification and restrained grain growth. Fast heating rate is helpful to retain more water in system at high temperature. Post-annealing, as a complementary step, can increase the density and crystallinity, eliminated second phase and amorphous phase, and thus improve material performances. CSP shows high potential in production of ceramic/ceramic or ceramic/polymer composites for a wide range of applications. To densify composite materials, at least one constitutes should be soluble to ensure the occurrence of dissolution-precipitation process.

Cathode composites fabricated by CSP exhibit higher volumetric capacity compared to that produced by conventional tape-casting. Ceramic electrolytes produced by CSP also show the improved density and ionic conductivity. The exploration of CSP is still at the early stage and the following challenges have to be addressed: (i) Low solubility of ceramics. As mentioned previously, the formation of hydrothermal environment completely depends on the dissolution of particle in the aqueous solution. The low solubility of ceramics greatly retards dissolution, and thus different aqueous solutions are yet to be optimised in order to increase solubility of ceramics. (ii) Formation of amorphous phase at grain boundaries. At the final stage of CSP, if the nucleation rate in metastable phase is higher than that in stable phases, an amorphous phase will be generated, which sometimes can decrease the performance of ceramics. Therefore, a post-annealing process is necessary to eliminate the amorphous phase. (iii) Complex mechanisms about CSP. The mechanisms of dissolution and precipitation process, and the kinetics of formation and elimination of glassy/amorphous phase are still not fully understood. (iv) Scalability of CSP. With increasing dimension of components, uniform distribution of pressure and temperature during CSP is more difficult to be achieved. Thus, it is challenging to scale up CSP.

Acknowledgements The authors thank Loughborough-China Materials Partnership Scholarship provided by Department of Materials, Loughborough University.

Open Access This article is licensed under a Creative Commons Attribution 4.0 International License, which permits use, sharing, adaptation, distribution and reproduction in any medium or format, as long as you give appropriate credit to the original author(s) and the source, provide a link to the Creative Commons licence, and indicate if changes were made. The images or other third party material in this article are included in the article's Creative Commons licence, unless indicated otherwise in a credit line to the material. If material is not included in the article's Creative Commons licence and your intended use is not permitted by statutory regulation or exceeds the permitted use, you will need to obtain permission directly from the copyright holder. To view a copy of this licence, visit http://creativecommons.org/licenses/by/4.0/.

\section{References}

1. Guo J, Guo H, Baker A L, Lanagan M T, Kupp E R, Messing G L, Randall C A. Cold sintering: A paradigm shift for processing and integration of ceramics. Angewandte Chemie International Edition, 2016, 55(38): 11457-11461

2. Guo H, Baker A, Guo J, Randall C A. Cold sintering process: A 
novel technique for low-temperature ceramic processing of ferroelectrics. Journal of the American Ceramic Society, 2016, 99(11): 3489-3507

3. Richerson D, Richerson D W, Lee W E. Modern Ceramic Engineering: Properties, Processing, and Use in Design. Roca Rato: CRC Press, 2005, 7-19

4. Zhang J, Zhang W, Zhao E, Jacques H J. Study of high-density AZO ceramic target. Materials Science in Semiconductor Processing, 2011, 14(3-4): 189-192

5. Han L Y, Shu Y C. Study of large-scale aluminium-doped zinc oxide ceramic targets prepared by slip casting. Advances in Materials Science and Engineering, 2016, 2016: 6410848

6. Chou Y H, Chau J L H, Wang W L, Chen C S, Wang S H, Yang C C. Preparation and characterization of solid-state sintered aluminumdoped zinc oxide with different alumina contents. Bulletin of Materials Science, 2011, 34(3): 477-482

7. Guillon O, Gonzalez-Julian J, Dargatz B, Kessel T, Schierning G, Räthel J, Herrmann M. Field-assisted sintering technology/spark plasma sintering: Mechanisms, materials, and technology developments. Advanced Engineering Materials, 2014, 16(7): 830-849

8. Kikuchi M, Kato T, Ohkura K, Ayai N, Fujikami J, Fujino K, Kobayashi S, Ueno E, Yamazaki K, Yamade S, et al. Recent development of drastically innovative BSCCO wire (DI-BISCCO). Physica C: Superconductivity and Its Applications, 2006, 445-448: $717-721$

9. Gu M L, Xu H, Zhang J, Wei Z, Xu A. Influence of hot pressing sintering temperature and time on microstructure and mechanical properties of $\mathrm{TiB}_{2} / \mathrm{TiN}$ tool material. Materials Science and Engineering A, 2012, 545: 1-5

10. Jaeger R E, Egerton L. Hot pressing of potassium-sodium niobates. Journal of the American Ceramic Society, 1962, 45(5): 209-213

11. Helle A S, Easterling K E, Ashby M F. Hot-isostatic pressing diagrams: New developments. Acta Metallurgica, 1985, 33(12): 2163-2174

12. Atkinson H V, Davies S. Fundamental aspects of hot isostatic pressing: An overview. Metallurgical and Materials Transactions. A, Physical Metallurgy and Materials Science, 2000, 31(12): 29813000

13. Cologna M, Rashkova B, Raj R. Flash sintering of nanograin zirconia in $<5 \mathrm{~s}$ at $850^{\circ} \mathrm{C}$. Journal of the American Ceramic Society, 2010, 93(11): 3556-3559

14. Cologna M, Prette A L G, Raj R. Flash-sintering of cubic yttriastabilized zirconia at $750^{\circ} \mathrm{C}$ for possible use in SOFC manufacturing. Journal of the American Ceramic Society, 2011, 94(2): 316-319

15. Munir Z A, Anselmi-Tamburini U, Ohyanagi M. The effect of electric field and pressure on the synthesis and consolidation of materials: A review of the spark plasma sintering method. Journal of Materials Science, 2006, 41(3): 763-777

16. Li J F, Wang K, Zhang B P, Zhang L M. Ferroelectric and piezoelectric properties of fine-grained $\mathrm{Na}_{0.5} \mathrm{~K}_{0.5} \mathrm{NbO}_{3}$ lead-free piezoelectric ceramics prepared by spark plasma sintering. Journal of the American Ceramic Society, 2006, 89(2): 706-709

17. Oghbaei M, Mirzaee O. Microwave versus conventional sintering: A review of fundamentals, advantages and applications. Journal of Alloys and Compounds, 2010, 494(1-2): 175-189

18. Upadhyaya D D, Ghosh A, Dey G K, Prasad R, Suri A K.
Microwave sintering of zirconia ceramics. Journal of Materials Science, 2001, 36(19): 4707-4710

19. Jiang J, Chen L, Bai S, Yao Q, Wang Q. Thermoelectric properties of textured $p$-type $(\mathrm{Bi}, \mathrm{Sb})_{2} \mathrm{Te}_{3}$ fabricated by spark plasma sintering. Scripta Materialia, 2005, 52(5): 347-351

20. Chaim R, Shen Z, Nygren M. Transparent nanocrystalline MgO by rapid and low-temperature spark plasma sintering. Journal of Materials Research, 2004, 19(9): 2527-2531

21. Zapata-Solvas E, Bonilla S, Wilshaw P R, Todd R I. Preliminary investigation of flash sintering of $\mathrm{SiC}$. Journal of the European Ceramic Society, 2013, 33(13-14): 2811-2816

22. Ohyanagi M, Yamamoto T, Kitaura H, Kodera Y, Ishii T, Munir Z A. Consolidation of nanostructured $\mathrm{SiC}$ with disorder-order transformation. Scripta Materialia, 2004, 50(1): 111-114

23. Van Dijen F K, Mayer E. Liquid phase sintering of silicon carbide. Journal of the European Ceramic Society, 1996, 16(4): 413-420

24. Sciti D, Bellosi A. Effects of additives on densification, microstructure and properties of liquid-phase sintered silicon carbide. Journal of Materials Science, 2000, 35(15): 3849-3855

25. Guo H, Guo J, Baker A, Randall C A. Hydrothermal-assisted cold sintering process: A new guidance for low-temperature ceramic sintering. ACS Applied Materials \& Interfaces, 2016, 8(32): 20909 20915

26. Guo H, Bayer T J M, Guo J, Baker A, Randall C A. Cold sintering process for 8 mol- $\% \mathrm{Y}_{2} \mathrm{O}_{3}$-stabilized $\mathrm{ZrO}_{2}$ ceramics. Journal of the European Ceramic Society, 2017, 37(5): 2303-2308

27. Zhao X, Guo J, Wang K, Herisson De Beauvoir T, Li B, Randall C A. Introducing a ZnO-PTFE (polymer) nanocomposite varistor via the cold sintering process. Advanced Engineering Materials, 2018, 20(7): 1700902

28. Guo J, Berbano S S, Guo H, Baker A L, Lanagan M T, Randall C A. Cold sintering process of composites: Bridging the processing temperature gap of ceramic and polymer materials. Advanced Functional Materials, 2016, 26(39): 7115-7121

29. Liu J A, Li C H, Shan J J, Wu J M, Gui R F, Shi Y S. Preparation of high-density $\mathrm{InGaZnO}_{4}$ target by the assistance of cold sintering. Materials Science in Semiconductor Processing, 2018, 84: 17-23

30. Byrappa K, Yoshimura M. Handbook of Hydrothermal Technology. Oxford: Elsevier, 2013, 29

31. Rahaman M N. Ceramic Processing. New York: CRC Press, 2017, 375-403

32. Hong W B, Li L, Cao M, Chen X M. Plastic deformation and effects of water in room-temperature cold sintering of $\mathrm{NaCl}$ microwave dielectric ceramics. Journal of the American Ceramic Society, 2018, 101(9): 4038-4043

33. Bouville F, Studart A R. Geologically-inspired strong bulk ceramics made with water at room temperature. Nature Communications, 2017, 8(1): 14655

34. Lewin S. The Solubility Product Principle: An Introduction to Its Uses and Limitations. London: Interscience Publishers, 1960, 1121

35. Seo J H, Guo J, Guo H, Verlinde K, Heidary D S B, Rajagopalan R, Randall C A. Cold sintering of a Li-ion cathode: $\mathrm{LiFePO}_{4}-$ composite with high volumetric capacity. Ceramics International, 2017, 43(17): 15370-15374

36. Gonzalez-Julian J, Neuhaus K, Bernemann M, Pereira da Silva J, 
Laptev A, Bram M, Guillon O. Unveiling the mechanisms of cold sintering of $\mathrm{ZnO}$ at $250^{\circ} \mathrm{C}$ by varying applied stress and characterizing grain boundaries by Kelvin probe force microscopy. Acta Materialia, 2018, 144: 116-128

37. Bendale P, Venigalla S, Ambrose J R, Verink E D Jr, Adair J H. Preparation of barium titanate films at $55^{\circ} \mathrm{C}$ by an electrochemical method. Journal of the American Ceramic Society, 1993, 76(10): 2619-2627

38. Funahashi S, Guo J, Guo H, Wang K, Baker A L, Shiratsuyu K, Randall C A. Demonstration of the cold sintering process study for the densification and grain growth of $\mathrm{ZnO}$ ceramics. Journal of the American Ceramic Society, 2017, 100(2): 546-553

39. Guo H, Baker A, Guo J, Randall C A. Protocol for ultralowtemperature ceramic sintering: An integration of nanotechnology and the cold sintering process. ACS Nano, 2016, 10(11): 1060610614

40. Wang D, Guo H, Morandi C S, Randall C A, Trolier-McKinstry S. Cold sintering and electrical characterization of lead zirconate titanate piezoelectric ceramics. APL Materials, 2018, 6(1): 016101

41. Ma J P, Chen X M, Ouyang W Q, Wang J, Li H, Fang J L. Microstructure, dielectric, and energy storage properties of $\mathrm{BaTiO}_{3}$ ceramics prepared via cold sintering. Ceramics International, 2018, 44(4): 4436-4441

42. Hakuta Y, Ura H, Hayashi H, Arai K. Continuous production of $\mathrm{BaTiO}_{3}$ nanoparticles by hydrothermal synthesis. Industrial \& Engineering Chemistry Research, 2005, 44(4): 840-846

43. Yosenick T. Synthesis and colloidal properties of anisotropic hydrothermal barium titanate. Dissertation for the Doctoral Degree. Pennsylvania: Pennsylvania State University, 2005, 16-20

44. Boston R, Guo J, Funahashi S, Baker A L, Reaney I M, Randall C A. Reactive intermedihate phase cold sintering in strontium titanate. RSC Advances, 2018, 8(36): 20372-20378

45. Berbano S S, Guo J, Guo H, Lanagan M T, Randall C A. Cold sintering process of $\mathrm{Li}_{1.5} \mathrm{Al}_{0.5} \mathrm{Ge}_{1.5}\left(\mathrm{PO}_{4}\right)_{3}$ solid electrolyte. Journal of the American Ceramic Society, 2017, 100(5): 2123-2135

46. Sato T, Shimada M. Transformation of ceria-doped tetragonal zirconia polycrystals by annealing in water. American Ceramic Society Bulletin, 1985, 64(10): 1382-1384

47. Guo H, Bayer T J M, Guo J, Baker A, Randall C A. Current progress and perspectives of applying cold sintering process to $\mathrm{ZrO}_{2}$-based ceramics. Scripta Materialia, 2017, 136: 141-148

48. Leng $\mathrm{H}$, Huang J, Nie J, Luo J. Cold sintering and ionic conductivities of $\mathrm{Na}_{3.256} \mathrm{Mg}_{0.128} \mathrm{Zr}_{1.872} \mathrm{Si}_{2} \mathrm{PO}_{12}$ solid electrolytes. Journal of Power Sources, 2018, 391: 170-179

49. Neves N, Barros R, Antunes E, Calado J, Fortunato E, Martins R, Ferreira I. Aluminum doped zinc oxide sputtering targets obtained from nanostructured powders: Processing and application. Journal of the European Ceramic Society, 2012, 32(16): 4381-4391

50. Munz D, Fett T. Ceramics: Mechanical Properties, Failure Behaviour, Materials Selection. New York: Springer Science \& Business Media, 2013, 137-154

51. Xu J, Yang Z, Zhang X, Wang H, Xu H. Grain size control in ITO targets and its effect on electrical and optical properties of deposited ITO films. Journal of Materials Science Materials in Electronics, 2014, 25(2): 710-716

52. Jing Y, Luo N, Wu S, Han K, Wang X, Miao L, Wei Y. Remarkably improved electrical conductivity of $\mathrm{ZnO}$ ceramics by cold sintering and post-heat-treatment. Ceramics International, 2018, 44(16): 20570-20574

53. Wang D, Zhou D, Zhang S, Vardaxoglou Y, Whittow W G, Cadman $\mathrm{D}$, Reaney I M. Cold-sintered temperature stable $\mathrm{Na}_{0.5} \mathrm{Bi}_{0.5} \mathrm{MoO}_{4}$ $\mathrm{Li}_{2} \mathrm{MoO}_{4}$ microwave composite ceramics. ACS Sustainable Chemistry \& Engineering, 2018, 6(2): 2438-2444

54. Induja I J, Sebastian M T. Microwave dielectric properties of mineral sillimanite obtained by conventional and cold sintering process. Journal of the European Ceramic Society, 2017, 37(5): 2143-2147

55. Induja I J, Sebastian M T. Microwave dielectric properties of cold sintered $\mathrm{Al}_{2} \mathrm{O}_{3}-\mathrm{NaCl}$ composite. Materials Letters, 2018, 211: 5557

56. Guo J, Guo H, Heidary D S B, Funahashi S, Randall C A. Semiconducting properties of cold sintered $\mathrm{V}_{2} \mathrm{O}_{5}$ ceramics and Cosintered $\mathrm{V}_{2} \mathrm{O}_{5}$-PEDOT:PSS composites. Journal of the European Ceramic Society, 2017, 37(4): 1529-1534

57. Guo J, Pfeiffenberger N, Beese A, Rhoades A, Gao L, Baker A, Wang K, Bolvari A, Randall C A. Cold sintering $\mathrm{Na}_{2} \mathrm{Mo}_{2} \mathrm{O}_{7}$ ceramic with polyetherimide (PEI) polymer to realize high performance composites and integrated multilayer circuits. ACS Applied Nano Materials, 2018, 1(8): 3837-3844

58. Heidary D S B, Guo J, Seo J H, Guo H, Rajagopalan R, Randall C A. Microstructures and electrical properties of $\mathrm{V}_{2} \mathrm{O}_{5}$ and carbonnanofiber composites fabricated by cold sintering process. Japanese Journal of Applied Physics, 2018, 57(2): 025702

59. Guo H, Guo J, Baker A, Randall C A. Cold sintering process for $\mathrm{ZrO}_{2}$-based ceramics: Significantly enhanced densification evolution in yttria-doped $\mathrm{ZrO}_{2}$. Journal of the American Ceramic Society, 2017, 100(2): 491-495

60. Seo J H, Verlinde K, Guo J, Heidary D S B, Rajagopalan R, Mallouk $\mathrm{T}$ E, Randall C A. Cold sintering approach to fabrication of high rate performance binderless $\mathrm{LiFePO}_{4}$ cathode with high volumetric capacity. Scripta Materialia, 2018, 146: 267-271

61. Nakaya H, Iwasaki M, Herisson de Beauvoir T, Randall C A. Applying cold sintering process to a proton electrolyte material: $\mathrm{CsH}_{2} \mathrm{PO}_{4}$. Journal of the European Ceramic Society, 2019, 39(2-3): 396-401

62. Baker A, Guo H, Guo J, Randall C. Utilizing the cold sintering process for flexible-printable electroceramic device fabrication. Journal of the American Ceramic Society, 2016, 99(10): 3202-3204

63. Mazaheri M, Zahedi A M, Sadrnezhaad S K. Two-step sintering of nanocrystalline $\mathrm{ZnO}$ compacts: Effect of temperature on densification and grain growth. Journal of the American Ceramic Society, 2008, 91(1): 56-63

64. Cheng H, Xu X J, Hng H H, Ma J. Characterization of Al-doped $\mathrm{ZnO}$ thermoelectric materials prepared by RF plasma powder processing and hot press sintering. Ceramics International, 2009, 35 (8): 3067-3072

65. Seiyama T, Yamazoe N, Arai H. Ceramic humidity sensors. Sensors and Actuators, 1983, 4: 85-96

66. Abraham K M, Jiang Z. A polymer electrolyte-based rechargeable lithium/oxygen battery. Journal of the Electrochemical Society, 1996, 143(1): 1-5

67. Capsoni D, Bini M, Ferrari S, Quartarone E, Mustarelli P. Recent 
advances in the development of Li-air batteries. Journal of Power Sources, 2012, 220: 253-263

68. Meier K, Laino T, Curioni A. Solid-state electrolytes: Revealing the mechanisms of Li-ion conduction in tetragonal and cubic LLZO by first-principles calculations. Journal of Physical Chemistry C, 2014, 118(13): 6668-6679

69. Zhang X F, Wang K X, Wei X, Chen J S. Carbon-coated $\mathrm{V}_{2} \mathrm{O}_{5}$ nanocrystals as high performance cathode material for lithium ion batteries. Chemistry of Materials, 2011, 23(24): 5290-5292

70. Park K I, Song H M, Kim Y, Mho S, Cho W I, Yeo I H. Electrochemical preparation and characterization of $\mathrm{V}_{2} \mathrm{O}_{5}$ /polyaniline composite film cathodes for Li battery. Electrochimica Acta, 2010, 55(27): 8023-8029

71. Richards W D, Miara L J, Wang Y, Kim J C, Ceder G. Interface stability in solid-state batteries. Chemistry of Materials, 2016, 28(1): 266-273

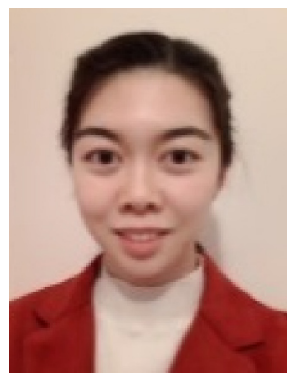

Tong $\mathrm{Yu}$ is pursuing her $\mathrm{PhD}$ degree in Materials under the supervision of Dr. Xujin Bao and Dr. Hongtao Zhang at Department of Materials, Loughborough University, UK. She attained her BSc degree in Biomaterials from Beijing University of Chemical Technology and MSc degree in Polymer Science and Technology from Loughborough University. Her current research interests focus on cold sintering process to produce transparent conducting oxides targets, solid-state electrolytes and ceramic-polymer electrolytes for all-solid-state $\mathrm{Li}$-ion batteries.

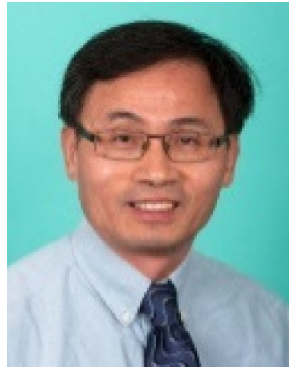

Dr. Xujin Bao attained a BSc and MEng from the department of Materials Science and Engineering at South China University of Technology, China. He then worked as a lecturer in Beijing University of Chemical Technology for six years. He completed his $\mathrm{PhD}$ in Materials Chemistry at Northumbria University in 1997. He worked as research assistant in Brunel University, Loughborough University and Queen Mary University of London. He became a lecturer in 2000 then senior lecturer 2006 in the Department of Materials at Loughborough University, UK. His research interests cover hybrid composites and functional materials via novel synthetic methods, cold sintering of functional ceramics. 